\title{
A Reassessment of the Analysis Provisions for Bond and Anchorage Length of Deformed Reinforcing Bars in Tension
}

\author{
M.H. Mazumder, R.I. Gilbert and Z.T. Chang
}

\begin{abstract}
Analysis and design provisions for the bond and anchorage length of deformed reinforcing bars in reinforced concrete elements are typically developed based on the assumption that the strain variations along the bar becomes approximately linear at or near the ultimate state of bond failure. Hence the assumption of the development of uniform bond stress along the anchorage length is used to calculate anchorage lengths of bars regardless of the variations in anchorage lengths or bar diameter. This paper describes an ongoing experimental research program in the Centre for Infrastructure Engineering and Safety (CIES) at the University of New South Wales, Sydney aimed at assessing the effects of different structural factors on the anchorage requirements of modern high strength steel reinforcing bars, including the cases of end development and lapped splices of deformed bars in tension. While the fundamental assumption of uniform bond stress development could be justified for relatively shorter anchorage length, the study found that an increase in anchorage length and bar diameter leads to a reduction of average ultimate bond stress which might be due to the non-uniformity in the development of bond stress along the anchorage zone. It is shown in this paper that the variability in the development of bond stress due to variable anchorage lengths is associated with the variable degree of plastic deformation in the concrete's tensile zone. This paper outlines the importance of these effects on the development of analysis and design guidelines for anchorage of reinforcement.
\end{abstract}

Keywords--- Bond Stress, Development Length, Lapped Splice Length, Reinforcement, Slip

M.H. Mazumder, PhD Student, Centre for Infrastructure Engineering and Safety, School of Civil and Environmental Engineering, The University of New South Wales, Sydney, NSW 2052, Australia. Email:z3319514@student.unsw.edu.au

R.I. Gilbert, Emeritus Professor, Centre for Infrastructure Engineering and Safety, School of Civil and Environmental Engineering, The University of New South Wales, Sydney, NSW 2052, Australia. Email:i.gilbert@unsw.edu.au

Z.T. Chang, Research Associate, Centre for Infrastructure Engineering and Safety, School of Civil and Environmental Engineering, The University of New South Wales, Sydney, NSW 2052, Australia. Email:z.chang@unsw.edu.au

\section{INTRODUCTION}

$\mathrm{W}$ HEN designing a reinforced concrete (RC) member for strength, ductility and robustness, it is essential that the tensile reinforcement at the critical section can not only develop the yield stress of the steel, $\mathrm{f}_{\mathrm{sy}}$, but that it can sustain that level of stress as deformation increases. If $f_{s y}$ is to be reached and maintained, a minimum length of reinforcing bar (the development length) is required on either side of the critical section. In the general design guidelines of RC elements, a minimum development length, $\mathrm{L}_{\mathrm{sy} . \mathrm{t}}$, is specified over which a straight bar must be embedded in the concrete in order to develop its yield stress. In real structures, where loads may be repetitive and dynamic in nature, where different cracking patterns and frequencies along the anchorage lengths may reduce the average ultimate bond stress and where deterioration may occur due to extensive periods of exposure to the elements, the anchorage requirements of reinforcement may not be the same. When such structures are subjected to extreme events, failure of the anchorage of the reinforcement is often the trigger that initiates collapse.

An extensive experimental program is underway at the University of New South Wales to assess the impact of static, cyclic and sustained loading on the anchorage requirements of modern high strength steel reinforcing bars, including the case of end development and lapped splices of reinforcing bars in tension. The research is aimed at quantifying the effects of the important parameters that affect the stress development in reinforcing bars and hence influence the bond stress that is mobilized along the anchorage length. Factors identified in previous experimental studies that affect the bond strength, including the concrete cover, bar spacing and bar diameter, are being reassessed, and their effect on anchorage length for different loading conditions and structural geometries are being examined. The ultimate objective of the project is to develop procedures for anchoring reinforcement in RC structures that provide reliable and consistent factors of safety and that allow structures to be robust throughout their design life, without an increase in risk of premature collapse through bond and anchorage failure.

This paper describes the first of the four stages of the experimental research program aimed at assessing the impact of static and cyclic loading on the development length of Grade N Australian deformed bars. Based on the results of the first stage of the research, a critical assessment of some fundamental analysis and design provisions for the bond and anchorage length is made. 


\section{Theoretical AND PRActical Aspects of Bond AND ANCHORAGE LENGTH}

\subsection{General Overview and Codes of Practices}

When the tensile force in a bar is increased and the adhesive bond between the steel and the concrete is broken, some frictional slip takes place before the full bearing capacity at a rib is mobilized. Within the development length of a deformed bar, the deformations progressively bear onto the surrounding concrete and the bearing forces $\mathrm{F}$ are inclined at an angle $\beta$ to the bar axis as shown in Figure 1a [1]. The horizontal component of this bearing force mobilizes the bond stress, $\mathrm{f}_{\mathrm{b}}$ at the interface between concrete and reinforcement. The perpendicular component of the bearing forces exerts a radial force on the surrounding concrete. Tepfers [2, 3, and 4] described the concrete in the vicinity around the bar as acting like a thick walled pipe as shown in Figure $1 \mathrm{~b}$. and the radial forces exerted by the bar cause tensile stresses, $\sigma_{r}$ (Figure 2) that may lead to splitting cracks radiating from the bar if the tensile strength of the concrete is exceeded. Bond failure is typically initiated by the splitting cracks within the development length of an anchored bar (Figure 1c and 1d) or within the lap-length at a lapped tension splices (Figure 1e). The bar pull-out due to increasing slip between the concrete and reinforcement is also concurrently associated with the splitting phenomena. Transverse reinforcement across the splitting planes ( $A_{t r}$ in Figure 1c, 1d and 1e) delays the propagation of cracks and improves bond strength. Compressive pressure transverse to the plane of splitting delays the onset of cracking thereby improves bond strength.
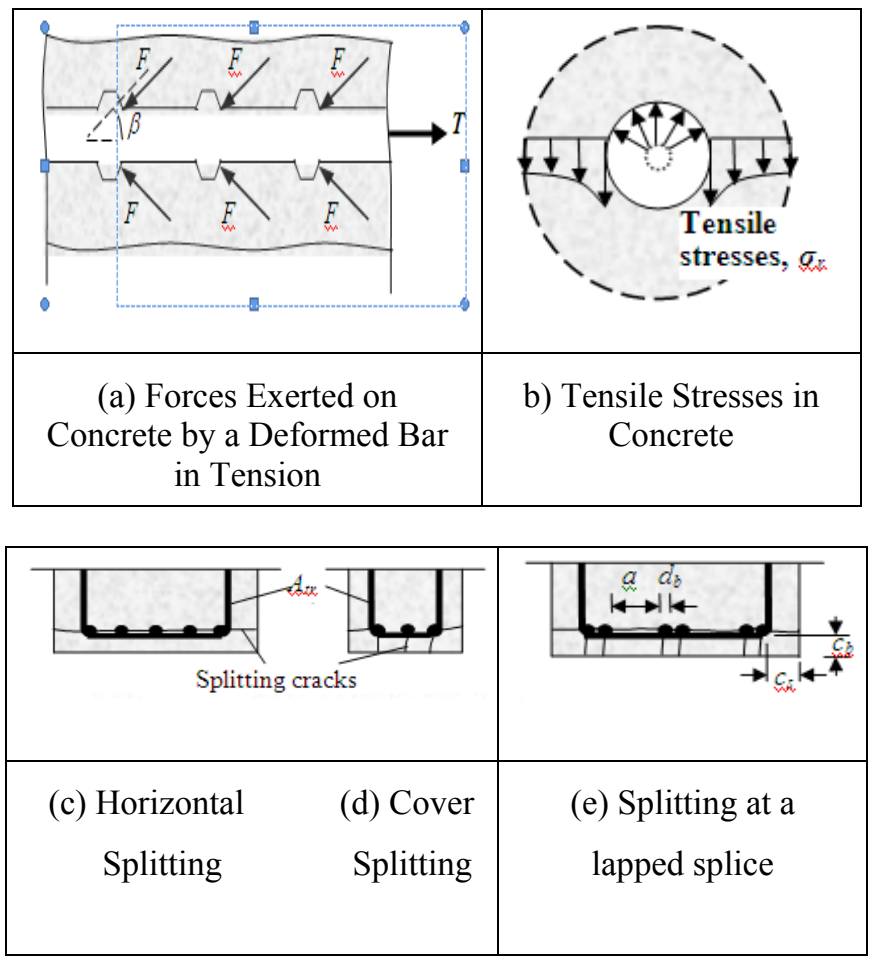

Figure 1: Splitting Failures around Developing Bars [3]

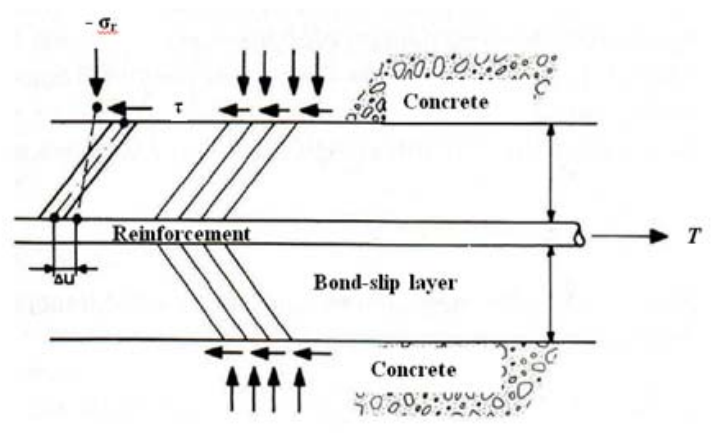

Figure 2: Mechanical Bearing Forces on Rib Idealized in a Bond Slip Model [5]

Codes of practice $[6,7$, and 8$]$ specify a minimum development length, $L_{s y . t}$. The fundamental requirement is that for a reinforcing bar of diameter $d_{b}$, the ultimate bond force over the development length $\left(\pi d_{b} L_{s y . t} f_{u b}\right)$ must not be less than the maximum bar force $\left(f_{s y} A_{s t}=f_{s y} \pi d_{b}^{2} / 4\right)$. Therefore,

$$
L_{s y . t} \geq 0.25 d_{b} f_{s y} / f_{u b}
$$

Expressions for the development length in most codes of practice are similar to (1) with the average ultimate bond stress, $f_{u b}$ directly related to the tensile strength of concrete, $f^{\prime}{ }_{t}$ and modified by coefficients of varying form and complexity to account for the factors affecting bond strength. However, the specified values for $L_{s y . t}$ in the major international Standards differ widely [9] and have been developed independently as empirical fits to experimental data obtained from tests involving monotonically increasing static loads often on small scale specimens.

\subsection{Empirical Analytical Models of Bond and Anchorage}

In many of the analytical models, the angle $\beta$ is used as the key parameter for describing the relationship between $\sigma_{\mathrm{r}}$ and the average ultimate bond stress at failure, $f_{\mathrm{ub}}$. These empirical models also have in common the dimensionless parameter $c / d_{\mathrm{b}}$ as the correlation parameter to the normalized bond strength parameter, $f_{\mathrm{ub}} /\left(f^{\prime}{ }_{\mathrm{c}}\right)^{0.5}$, where $c$ is the minimum of the side or bottom thickness of concrete cover around a reinforcing bar.

Ferguson \& Briceno [10] developed equations for side split and face-and-side split bond failures assuming that the radial and longitudinal components of force between the bar and concrete are equal $\left(\beta=45^{\circ}\right)$. One of the main limitations of their approach is that the splitting was assumed to occur instantaneously along the anchorage length. However, splitting is actually progressive, starting at the critical end of the anchorage. The crude assumption of the value of $\beta$ also disregards the observed uneven distribution of bond stress along the anchorage length.

Ferguson \& Krishnaswamy [11] used a slightly different approach and assumed that the splitting force is related to bond force but may not be equal to it (i.e. $\beta$ may be more or less than $45^{\circ}$ ). They took the concrete tensile strength $f^{\prime}{ }_{t}=$ $0.531\left(f^{\prime}{ }^{\prime}\right)^{0.5}$ (in MPa), a value based on split cylinder tests.

By applying the thick cylinder theory, Tepfers [2, 3, 4] derived a relationship between radial splitting forces at failure and $f^{\prime}{ }_{\mathrm{t}}$. The radial stress, $\sigma_{\mathrm{r}}$ was regarded as the pressure 
acting against the thick walled cylinder while the inner diameter of the cylinder was considered as the reinforcing bar diameter. Tepfers [2] assumed the thick wall of concrete around the deformed bar in tension is cracked and the maximum depth of internal crack, $e$, was shown to be $0.486\left(c+d_{\mathrm{b}} / 2\right)$. The outer zone of concrete around the cylinder was assumed to be uncracked and fully elastic with the bond force carried to it through the cracked concrete. While comparing the bond action at the elastic, plastic and partly cracked elastic stages, Tepfers [2] assumed that the angle $\beta$ is the same at all the above stages.

Hence the criteria for the occurrence of ultimate load in the concrete ring around the reinforcing bar were set as follows:

i) Elastic stage: Maximum tensile stress peak exceeds ultimate tensile stress for the concrete.

ii) Plastic stage: The tensile stress evenly distributed over the concrete cover exceeds the ultimate tensile stress for the concrete.

Tepfers showed the maximum tensile stress due to the bond action was $(\sigma r) \max =\left(1.664 \mathrm{f}_{\mathrm{ub}} d_{\mathrm{b}} \tan \beta\right) /\left(\mathrm{c}+d_{\mathrm{b}} / 2\right)$. Bond failure is assumed to occur as soon as the maximum tensile stress in the concrete is equal to $f_{t}^{\prime}$. That is:

$$
f^{\prime}=\left(1.664 f_{\mathrm{ub}} d_{\mathrm{b}} \tan \beta\right) /\left(c+d_{\mathrm{b}} / 2\right)
$$

Since $f^{\prime}{ }_{\mathrm{t}}$ can be written as $k_{1}\left(f^{\prime}{ }_{\mathrm{c}}\right)^{0.5}$, then

$$
c / d_{\mathrm{b}}+1 / 2=1.664 f_{\mathrm{ub}} \tan \beta / k_{1}\left(f^{\prime}{ }^{\prime}\right)^{0.5}
$$

The main criticism of the Tepfers' thick cylinder theory is that concrete does not behave wholly elastically in tension at failure. Hence, the application of the thick cylinder theory may not be entirely valid. Assuming a full plastic behavior in the uncracked section of the concrete, Orangun et al. [12] showed that the maximum tensile stress in the uncracked section is $\left(0.972 \mathrm{f}_{\mathrm{ub}} d_{\mathrm{b}} \tan \beta\right) /\left(\mathrm{c}+\mathrm{d}_{\mathrm{b}} / 2\right)$. In the range of $\mathrm{f}$ 'c considered by Ferguson and Krishnaswamy [11], $f^{\prime}{ }_{t}=0.531$ (f 'c) 0.5 which results in a value of $\tan \beta=0.77$ for the full elastic behavior, whereas that as for the plastic behavior is $\tan \beta=1.32$. In reality, the angle $\beta$ changes in magnitude as bond failure develops due to progressive crushing of concrete in front of the bar deformation and this also changes the mechanical wedging action between the bar and concrete.

\subsection{Bond-Slip Models for Numerical Modeling}

The bond stress that develops at the contact surface between the reinforcing bar and concrete, $f_{\mathrm{b}}$, is the component of the radial tensile stress, $\sigma_{\mathrm{r}}$ in the direction of the bar and may be expressed as

$f_{\mathrm{b}}=-\sigma_{\mathrm{r}} \tan \beta=-\mathrm{k} \sigma_{\mathrm{r}}$

Where $\mathrm{k}(=\tan \beta)$ is the so called rib factor which represents the effects of the deformations on the surface of the bar, i.e. mechanical interlocking [1]. In the bond-slip model, $f_{\mathrm{b}}$ is associated with the slip at the bar-concrete interface and constitutive laws for the bond-slip relationship are typically developed from empirical expressions that best fit the relevant experimental results.

When modeling RC structures with the finite element method, the displacement field at the bar-concrete interface is determined using mathematical expressions that describe the mechanical relation between $\sigma_{r}$ and $f_{\mathrm{b}}$ through the rib factor, $\mathrm{k}$. Bond-slip constitutive laws, such as that shown in Figure 3, are typically implemented at the bar-concrete interface. The rib factor, $\mathrm{k}$ is normally built into the structural modeling software as a constant value.

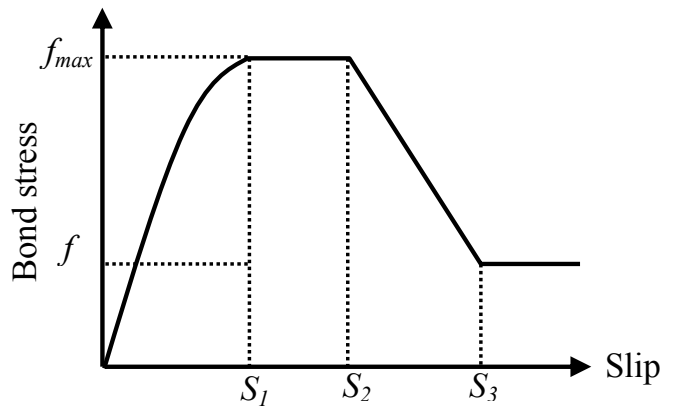

Figure 3: Typical Bond-Slip Model of CEB-FIP 1990 [13]

Bond-slip relationships are, in general, developed from empirical fits to experimental data. The database, used for this purpose, mostly contains results from bar pull-out tests. At failure in a bar pull-out test, reinforcing bars embedded in the concrete specimen are axially loaded until bar pull-out bond failure occurs. The concrete between the bar deformations often shears and sliding (slip) occurs on the slip surface shown in Figure 4a.

Constitutive laws developed as empirically fits to the bar pull-out test results are based on the assumption that bond stresses are dependent solely on the slip. However, bond action causes not only bond stresses, but also splitting stresses, as was shown by Tepfers [6, 7, and 8]. The splitting stresses also change in magnitude and direction due to progressive crushing of concrete in front of the lugs of reinforcement. As the deposition of crushed concrete in front of the lugs changes the angle of inclination of the sliding surface (Figure 4b), the slip values also change in relation to the variable splitting stresses. According to Lutz and Gergely [14], concrete crushing in front of the ribs results in a new sliding surface and hence causes a change in the angle of inclination of the bar forces to the concrete (Figure 4b). The new sliding surfaces progressively cause larger splitting forces and hence smaller bond strengths.

In typical geometrical shapes of RC structures, for example in beams and slabs, exclusive bar pull-out bond failures shown in Figure 4a is relatively rare. In most cases, bond failures with face splitting or face-and-side splitting of the concrete covers around the reinforcement are more usual. It follows that bond-slip constitutive laws should include the effects of splitting stresses into the basic formulation.

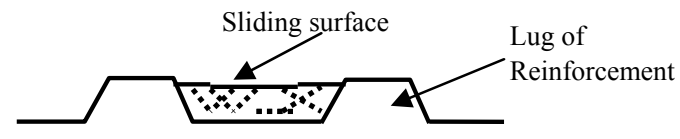

(a) Exclusive Bar Pull-Out Bond Failure 


\section{(b) Splitting Associate Bond Failure}

Figure 4: Bond Failure by Bar Pull-Out and Cover Splitting

The splitting stresses associated with splitting cracks in the concrete reduce the bond capacity. The yielding of reinforcement also reduces the bond capacity but not to the same extent that the splitting cracks do. Lundgren and Gilltoft [15] pointed out the difference between them and hence developed model for the bond between concrete and reinforcement which could generate various bond-slip model on demand under the various loading and geometrical arrangement of RC structures.

The loss of bond capacity being dependent on variable splitting stresses may not be the same for the different variations of anchorage lengths. This paper is aimed at evaluating the bond capacity of deformed reinforcing bars in tension where the bond failures are associated simultaneously with both bar pull-out and splitting of the cover concrete.

\section{THE EXPERIMENTAL PROGRAM}

\subsection{Test Specimens and Loading Regime}

The development length specimens were $2000 \mathrm{~mm}$ long, $600 \mathrm{~mm}$ wide and $200 \mathrm{~mm}$ deep. With supports $1200 \mathrm{~mm}$ apart, these statically determinate members were cantilevered at one end by an amount of $700 \mathrm{~mm}$, as shown in Figure 5a. The line load $P$ was $600 \mathrm{~mm}$ past Support 1. Each specimen contains four reinforcement bars in the top of the specimen, the outer two bars being terminated with a $180^{\circ} \operatorname{cog}$ immediately past Support 1 . For the two centrally placed bars that carry bending in the cantilever, the bond between the concrete and the bars was eliminated from the point of development length, $l_{d}$ past Support 1 through to the far end of the specimen by encasing each bar in a plastic sleeve. The bar within the plastic sleeve continues along the specimen, protruding from the right hand end. For the convenience during testing, the specimen is inverted so the anchored bars are located in the bottom of the specimen (see Figure 5c). A total of eighteen development length specimens were tested in Test Series 1. Fourteen specimens were tested under shortterm static loading and the remaining was tested under a cyclic loading regime.

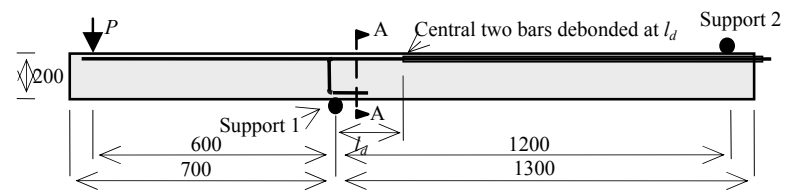

(a) Elevation of Specimen

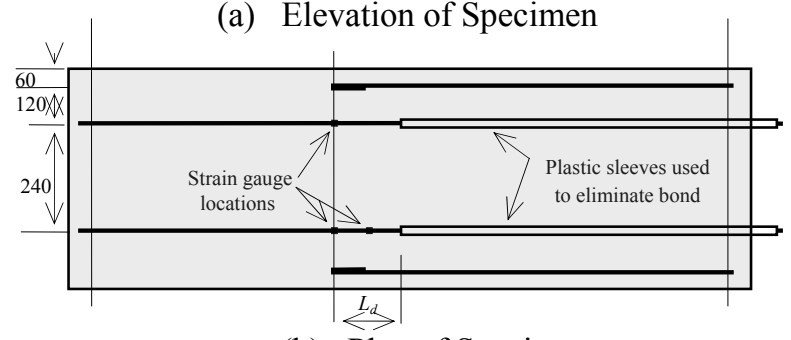

(b) Plan of Specimen

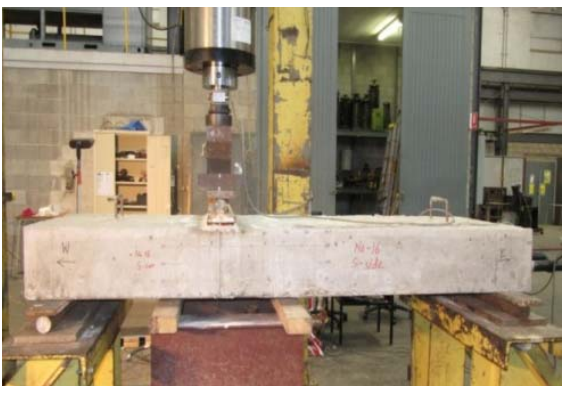

(c) Inverted Testing Arrangement

Figure 5: Dimensions and Loading Arrangements of Development Length Specimens

The static loading involved monotonically increasing the applied load on the specimen by controlling the rate of deformation at a suitably slow rate until failure occurs in the specimen, either by bond failure or yielding of the reinforcement. The cyclic loading involved repeatedly loading and unloading the specimen from $10 \%$ to about $50 \%$ of its static strength. Each cyclic loading specimen was subjected to in excess of 50,000 cycles of loading at a rate of 1.0 hertz. The deflection of the specimen at the point of load application, together with the slip at the end of the debonded bars, was measured throughout the test using LVDTs. Also measured throughout the test were the location of the primary cracks and crack widths. The variables considered were the bar diameter $d_{b}=12$ or $16 \mathrm{~mm}$; the development length $l_{d}=5 d_{\mathrm{b}}, 10 d_{b}, 15 d_{b}$ and $20 d_{b}$; and the bottom concrete cover $c=25$ or $40 \mathrm{~mm}$. Strain gauges were used to monitor steel strains in the developing bar at the critical cross-section and mid-way along the length $l_{d}$, as shown in Figure $5 \mathrm{~b}$. When interpreting the results of the static load tests, cracked section analysis can be readily undertaken to determine the stresses that develop in the developing bars at the critical cross- (Support 1) at all levels of applied loading up to and including anchorage failure.

\subsection{Test Results of Development Length Specimens}

The maximum load $P_{\max }$ applied to each specimen during the test is given in Table 1, together with the maximum stress in the monitored bars at the critical section and the average ultimate bond stress $f_{\text {ub }}$ over the anchorage length $l_{\mathrm{d}}$. Table 2 shows the material properties measured at the time of testing. 
When considering the minimum development lengths specified in codes of practice, it is generally agreed that a factor of safety in the range of 1.5 to 2.5 is reasonable and appropriate. For the static load tests, the factor of safety obtained from the Australian Standard, AS3600-2009 are generally in that range (except for DL-11 and DL-12 marginally under and DL-6 somewhat higher). With the exception of DL-4, the cyclic load tests are below the acceptable range. Specimen DL-14 with an anchorage length of just $60 \mathrm{~mm}\left(l_{\mathrm{d}}=5 d_{\mathrm{b}}\right)$ suffered bond failure immediately at first cracking. Of the cyclic tests, specimens DL-4, DL-13 and DL-17 were all subjected to in excess of 50,000 cycles of load, before being loaded monotonically to failure.

Table 1: Test Results for Development Length Specimens

\begin{tabular}{|c|c|c|c|c|c|c|c|}
\hline \multirow{2}{*}{$\begin{array}{l}\text { Specimen } \\
\text { No. and } \\
\text { load type }\end{array}$} & \multirow{2}{*}{$c / d_{b}$} & \multirow{2}{*}{$\begin{array}{l}l_{d} \\
(\mathrm{~mm})\end{array}$} & \multirow{2}{*}{$\begin{array}{l}P_{\max } \\
(\mathrm{kN})\end{array}$} & \multicolumn{2}{|c|}{$\begin{array}{l}\text { At section at } \\
\text { support } 1 \text { under } \\
P_{\max }\end{array}$} & \multicolumn{2}{|c|}{ AS3600-2009 } \\
\hline & & & & $\begin{array}{l}\sigma_{s t} \\
(\mathrm{MPa})\end{array}$ & $\begin{array}{l}f_{u b} \\
(\mathrm{MPa})\end{array}$ & $\begin{array}{l}f_{u b} \\
(\mathrm{MPa})\end{array}$ & $\begin{array}{l}\text { Factor } \\
\text { of } \\
\text { safety }\end{array}$ \\
\hline DL-1 (S) & 1.56 & 160 & 30.5 & 308 & 7.69 & 3.93 & 1.96 \\
\hline DL-2 (S) & 1.56 & 240 & 40.5 & 403 & 6.72 & 3.93 & 1.71 \\
\hline DL-3 (S) & 1.56 & 320 & 48.3 & 478 & 5.97 & 3.93 & 1.52 \\
\hline DL-4 (C) & 1.56 & 240 & 44.9 & 445 & 7.41 & 3.93 & 1.89 \\
\hline DL-5 (S) & 1.56 & 240 & 42.8 & 425 & 7.09 & 3.93 & 1.80 \\
\hline DL-6 (S) & 2.08 & 120 & 27.2 & 477 & 11.92 & 4.45 & 2.68 \\
\hline DL-7 (S) & 2.08 & 180 & 32.5 & 565 & 9.41 & 4.45 & 2.12 \\
\hline DL-8 (S) & 2.08 & 240 & 30.8 & 537 & 6.72 & 4.45 & 1.51 \\
\hline DL-9 (C) & 2.08 & 180 & 20.7 & 369 & 6.16 & 4.45 & 1.38 \\
\hline DL-10 (S) & 2.50 & 160 & 25.9 & 292 & 7.31 & 4.55 & 1.61 \\
\hline DL-11 (S) & 2.50 & 240 & 34.8 & 387 & 6.44 & 4.55 & 1.42 \\
\hline DL-12 (S) & 2.50 & 320 & 43.8 & 482 & 6.02 & 4.55 & 1.32 \\
\hline DL-13 (C) & 2.50 & 240 & 31.9 & 356 & 5.93 & 4.55 & 1.30 \\
\hline DL-14 (S) & 3.33 & 60 & 15.2 & - & - & - & - \\
\hline DL-15 (S) & 3.33 & 120 & 21.4 & 422 & 10.54 & 5.21 & 2.03 \\
\hline DL-16 (S) & 3.33 & 180 & 26.3 & 510 & 8.50 & 5.21 & 1.63 \\
\hline DL-17 (C) & 3.33 & 180 & 21.8 & 429 & 7.15 & 5.21 & 1.37 \\
\hline DL-18 (S) & 1.25 & 180 & 23.3 & 390 & 6.50 & 3.79 & 1.72 \\
\hline
\end{tabular}

Table 2: Material Properties of Specimens

\begin{tabular}{l|c|c|c|c|c}
\hline Specimen No. & $\begin{array}{c}f_{c} \\
(\mathrm{MPa})\end{array}$ & $\begin{array}{c}f_{c t, f} \\
(\mathrm{MPa})\end{array}$ & $\begin{array}{c}E_{c} \\
(\mathrm{MPa})\end{array}$ & $\begin{array}{c}f_{s y} \\
(\mathrm{MPa})\end{array}$ & $\begin{array}{c}f_{s u} \\
(\mathrm{MPa})\end{array}$ \\
\hline DL-1 to 5 & 38.5 & 3.75 & 34700 & 546 & 731 \\
\hline DL-6 to 9 & 38.5 & 3.75 & 34700 & 561 & 721 \\
\hline DL-10 to 13 & 36.9 & 3.60 & 29300 & 546 & 731 \\
\hline DL- 14 to 18 & 36.9 & 3.60 & 29300 & 561 & 721 \\
\hline
\end{tabular}

Each cyclic load specimen was cycled between $10 \%$ and $50 \%$ of the peak static load determined from the identical static load specimens DL-2, DL-11 and DL-16, respectively. Specimen DL-9 suffered a sudden bond failure after 25,080 cycles of load.

The average ultimate bond stress $f_{\text {ub }}$ required by AS36002009 to develop the failure stress $\sigma_{\text {st }}$ is also shown in Table 1, together with the factor of safety associated with the code approach (taken as the ratio of the measured $f_{u b}$ to that specified by the Standard). Figure 6 illustrates selected data from Table 1 from which the effects of concrete cover and reinforcing bar diameter on the actual ultimate bond stress $\left(f_{\mathrm{ub}}\right)$ can be analyzed.

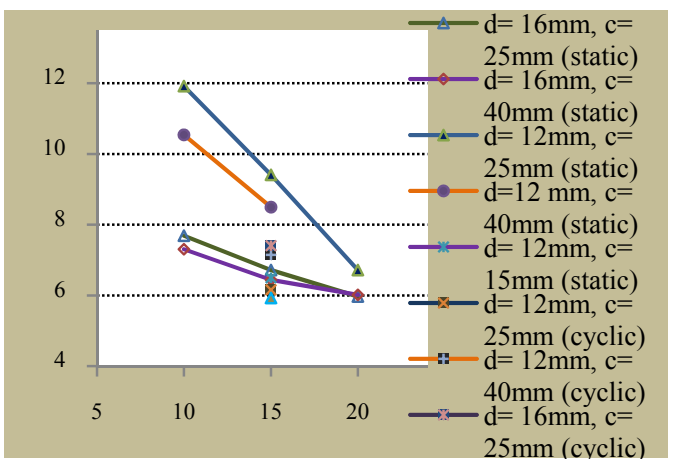

Figure 6: $f_{u b}$ for Different Bar Diameter and Covers of the Development Length Specimens

The followings summarize the main experimental observations:

- The effect of concrete cover on the development length is perhaps not as significant as is indicated in the current code approaches, with statistically little difference in steel stress at failure between the specimens with $25 \mathrm{~mm}$ and $40 \mathrm{~mm}$ cover.

- The effect of the dimensionless parameter, $c / d_{\mathrm{b}}$ on the average ultimate bond stress $f_{u b}$ is significant for the smaller diameter bars $(12 \mathrm{~mm})$ with the shorter anchorage lengths while for the larger diameter bars $(16 \mathrm{~mm})$ the effect is insignificant.

- The average bond stress at failure $f_{u b}$ decreases as the anchorage length $l_{d}$ increases. The measured value of $f_{u b}$ seems to be affected by the spacing and position of the primary cracks within the anchorage length.

- The values of $f_{u b}$ for $16 \mathrm{~mm}$ bars are significantly smaller than that for $12 \mathrm{~mm}$ bars, but the difference decreases for higher values of $l_{d}$. The relatively lower factors of safety for higher diameter bars is because more cracks form within the longer length ld and at each crack the local bond stress drops to zero, thereby reducing the average ultimate bond stress.

- The effect of cyclic loading on $f_{u b}$ is not clear. While the values of $f_{u b}$ for specimens DL- 13 and DL-17 were less than the values for their static load counterparts, the value for DL-4 was not.

\subsection{Further Discussion of Results}

The angle of inclination of the bearing forces within the anchorage length $(\beta)$ determined at the ultimate state of bond failure is indicative of the extent of plastic deformation that occurs at that state. Figure 7 is a plot of the normalized bond strength $\left(f_{\mathrm{ub}} /\left(f_{\mathrm{c}}^{\prime} \mathrm{c}\right)^{0.5}\right)$ against the dimensionless parameter $\mathrm{c} / \mathrm{db}$ for the test specimens together with points obtained from Tepfers' analytical solution using (3). The wide deviations of the experimental results from Tepfers' assumed linear behavior, particularly at higher values of bond stress, indicates that the assumption of fully elastic behavior of the concrete zone outside the assumed thick cylinder zone is not entirely valid. This also indicates the angle $\beta$ changes for the different variations of anchorage lengths and bars indicating variable degrees of plastic deformation. 


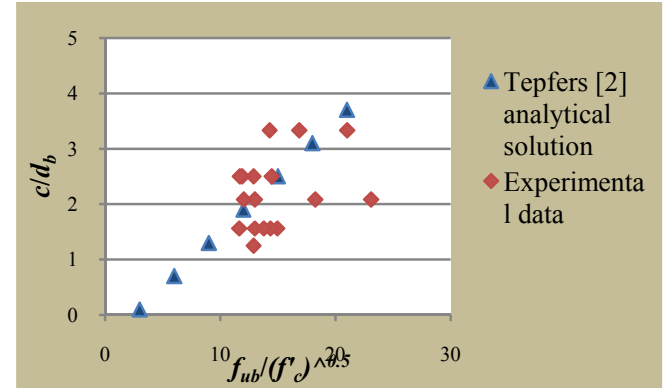

Figure 7: Comparison between Experimental Results and Tepfers' [2] Analytical Solution.

An optimization algorithm was implemented in order to minimize the difference between the experimental results of $f_{\mathrm{ub}}$ (exp) and the calculated values $\left(f_{\text {ub }}(\mathrm{cal})\right)$ so as to optimize the angle $\beta$ (or $\tan \beta$ ). The optimization was done assuming fully elastic and fully plastic behavior in the uncracked concrete around the anchored bar. The results are summarized in Table 3 . The optimized $\tan \beta$ values indicate the variable extent of plastic deformation that occurred in the concrete outside the assumed thick cylinder zone for different $c / d_{\mathrm{b}}$ ratios and for different anchorage lengths as well. For a particular $c / d_{\mathrm{b}}$ ratio, the variations of $\tan \beta$ values are due to the variations in development lengths.

Figure 8 shows that for different values of $c / d_{\mathrm{b}}$ there is a wide range of values of the angle $\beta$ (or $\tan \beta$ ). Expressions such as those shown in the figure can be used to choose the angle $\beta$ (or $\tan \beta$ ) for a particular $\mathrm{c} / \mathrm{db}$ ratio. However, further research is required to develop meaningful relationships between the angle $\beta(\tan \beta)$ and the parameters $c / d_{\mathrm{b}}$, the anchorage length ld and the bar diameter. The relationships developed from the experimental results could be effectively used for realistic prediction of the angle $\beta$ or the rib factor (k) and hence assist in developing more accurate formulations of bond and anchorage length to be used for practical purposes.

Table 3: Optimized $\tan \beta$ for Development Length Specimens

\begin{tabular}{|c|c|c|c|c|c|c|}
\hline \multirow[t]{2}{*}{$\begin{array}{c}\text { Specimen } \\
\text { no. }\end{array}$} & \multirow[t]{2}{*}{$c / d_{b}$} & \multirow[t]{2}{*}{$\begin{array}{c}l_{d} \\
(\mathrm{~mm})\end{array}$} & \multicolumn{2}{|c|}{$\begin{array}{l}\text { Optimization } \\
\text { assuming fully } \\
\text { elastic behaviour }\end{array}$} & \multicolumn{2}{|c|}{$\begin{array}{l}\text { Optimization } \\
\text { assuming fully } \\
\text { plastic behaviour }\end{array}$} \\
\hline & & & $\tan \beta$ & $\beta\left(^{\circ}\right)$ & $\tan \beta$ & $\beta\left(^{\circ}\right)$ \\
\hline DL-1 & 1.56 & 160 & 0.53 & 27.97 & 0.91 & 42.30 \\
\hline DL-2 & 1.56 & 240 & 0.61 & 23.85 & 1.04 & 46.15 \\
\hline DL-3 & 1.56 & 320 & 0.68 & 34.41 & 1.17 & 49.53 \\
\hline DL-4 & 1.56 & 240 & 0.55 & 28.89 & 0.94 & 43.35 \\
\hline DL-5 & 1.56 & 240 & 0.57 & 29.94 & 0.99 & 44.63 \\
\hline DL-6 & 2.08 & 120 & 0.43 & 23.22 & 0.74 & 36.32 \\
\hline DL-7 & 2.08 & 180 & 0.55 & 28.55 & 0.93 & 42.95 \\
\hline DL-8 & 2.08 & 240 & 0.76 & 37.27 & 1.30 & 52.52 \\
\hline DL-9 & 2.08 & 180 & 0.83 & 39.73 & 1.42 & 54.90 \\
\hline DL-10 & 2.50 & 160 & 0.80 & 38.52 & 1.36 & 53.73 \\
\hline DL-11 & 2.50 & 240 & 0.90 & 42.11 & 1.55 & 57.12 \\
\hline DL-12 & 2.50 & 320 & 0.97 & 44.04 & 1.66 & 58.86 \\
\hline DL-13 & 2.50 & 240 & 0.99 & 44.45 & 1.68 & 59.24 \\
\hline DL-15 & 3.33 & 120 & 0.70 & 35.07 & 1.21 & 50.36 \\
\hline DL-16 & 3.33 & 180 & 0.87 & 41.15 & 1.50 & 56.27 \\
\hline DL-18 & 1.25 & 180 & 0.52 & 27.56 & 0.89 & 41.80 \\
\hline
\end{tabular}

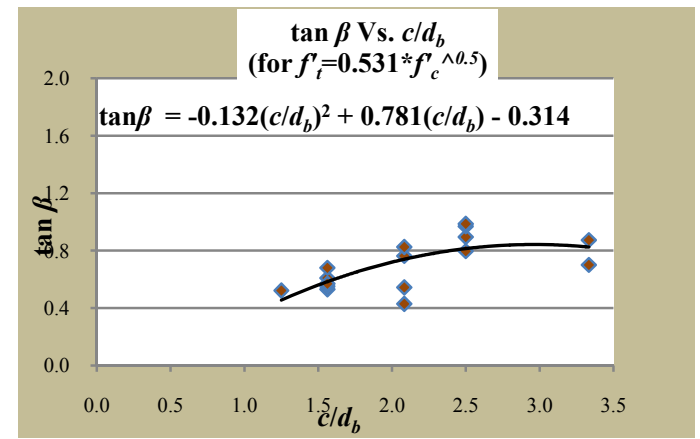

(a) Assuming Fully Elastic Behavior

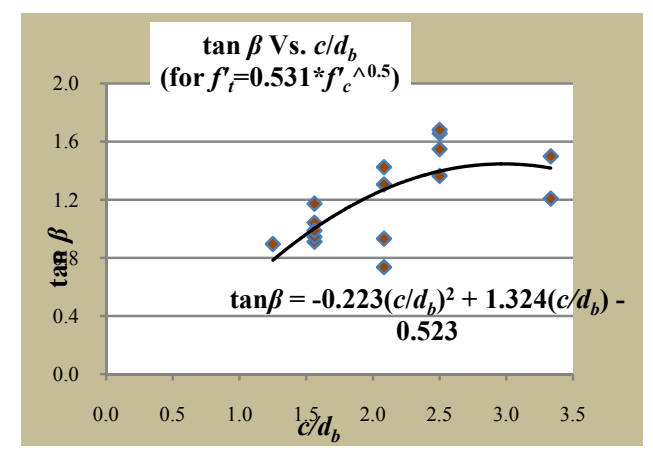

(b) Assuming Fully Plastic Behavior Figure 8: Optimized Solutions for $\tan \beta$ vs. c/db for Different Development Length Specimens

Figure 9 and Figure 10 show variations of measured strains in the reinforcement along the anchorage length $l_{d}$ of two specimens (DL-1 with $l_{d}=160 \mathrm{~mm}$ and DL-2 with $l_{d}=$ $240 \mathrm{~mm}$ ) at the ultimate state of bond failure (at $P_{\max }$ ). The figures are plotted assuming linear strain variations between the points where the strains were measured, i.e. at $l_{d}$ and $0.51 d$ from the end of the bar.

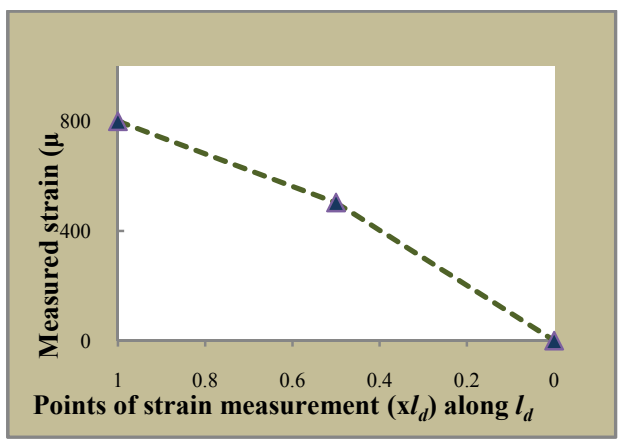

Figure 9: Strains in Reinforcement along $l_{d}$ in DL-1 (at $P_{\max }$ ) 


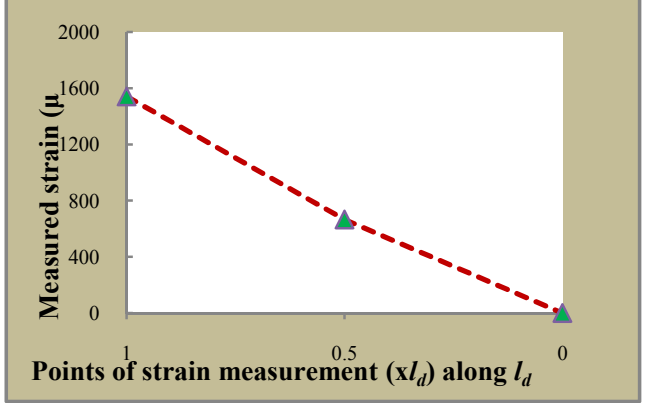

Figure 10: Strains in Reinforcement along $l_{d}$ in DL-2 (at $P_{\max }$ )

The comparison of Figure 9 and Figure 10 indicates that the half of the anchorage length closest to the end of the bar for the longer value of $l_{d}$ was relatively less effective for the development of stresses compared to the specimen with the shorter development length. For larger anchorage lengths, the portion of $l_{d}$ closest to the end of the bar becomes less effective. This is another reason for the reduction of the average ultimate bond stress, $f_{u b}$ in the relatively larger development length specimens.

\section{CONCLUSIONS}

The development length and the lapped splice length of deformed reinforcing bars in tension are typically calculated according to the procedures specified in the relevant local code of practice. According to the results presented in the paper, the effect of concrete cover on the development length is perhaps not as significant as is indicated in the code approaches. The reinforcing bar diameter, on the other hand, seems to strongly affect the average ultimate bond stress mobilized along the development length. The average ultimate bonds stress is also greatly affected by the anchorage length of the specimen. Shorter anchorage lengths develop higher average ultimate bond stress because fewer primary cracks cross the anchorage region. At each primary crack there is a local breakdown of bond, thus lowering the average bond that can develop over an anchorage length.

In addition, different structural factors, including the normalized parameter $\left(c / d_{b}\right)$, significantly affected the bearing angle $\beta$ and hence the extent of plastic behavior of the concrete in the tensile zone around the anchored bar. This phenomenon needs to be explored further in order to develop reliable bond-slip relationships and to recalibrate the bond models used in commercial software packages and for the development of reliable code procedures for bond and anchorage of deformed reinforcing bars in tension.

\section{ACKNOWLEDGMENT}

The work has been undertaken with the financial support of the Australian Research Council through an ARC Discovery grant to the second author. This support is gratefully acknowledged.

\section{REFERENCES}

[1] Y. Goto, "Cracks Formed in Concrete around Deformed Tension Bars", ACI Journal, Volume 68, Issue 4, Pp. 244-251, 1971.

[2] R. Tepfers, "A Theory of Bond Applied to Overlapped Tensile Reinforcement Splices for Deformed Bars", Publication 73:2, Division of Concrete Structures, Chalmers University of Technology, Goteborg, Sweden, 1973.

[3] R. Tepfers, "Cracking of Concrete Cover along Anchored Deformed Reinforcing Bars", Magazine of Concrete Research, Volume 31, Issue 106, Pp. 3-12, 1979.

[4] R. Tepfers, "Lapped Tensile Reinforcement Splices", Journal of Structural Division, Volume 108, Issue 1, Pp. 283-301, 1982.

[5] A.K. de Groot, G.M.A. Kusters and Th. Monnier, "Concrete Mechanics (Part B): Numerical Modelling of Bond-slip Behaviour", Heron, Volume 26, Issue 1a, Pp. 12-13, 1981.

[6] Standards Australia: Australian Standard for Concrete Structures (AS3600-2009), Sydney, Australia, 2009.

[7] ACI Committee 318: Building Code Requirements for Structural Concrete (ACI318M-08) and Commentary, American Concrete Institute, Farmington Hills, Michigan, 2008.

[8] Eurocode 2: Design of Concrete Structures Part 1-1: General Rules and Rules for Buildings, BS EN 1992-1-1:2004, European Committee for Standardisation, Brussels, 2004.

[9] R.I. Gilbert, "A Review and Critical Comparison of the Provisions for the Anchorage of Reinforcement in North American, European and Australian Standards", Concrete in Australia, Volume 33, Issue 3, Pp. 33-40, 2007.

[10] P.M. Ferguson and E.A. Briceno, "Tensile Lap Splices - Part 1: Retaining Wall Type, Varying Moment Zone", Research Report 113-2, Center for Highway Research, University of Texas at Austin, 1969.

[11] P.M. Ferguson and C.N. Krishnaswamy, "Tensile Lap Splices. - Part 2: Design Recommendations for Retaining Wall Splices", Research Report 113-3. Center for Highway Research, University of Texas at Austin, 1971.

[12] C.O. Orangun, J.O. Jirsa and J.E. Breen, "A Reevaluation of Test data on Development Length and Splices", ACI Journal, Volume 74, Issue 3, Pp. 114-122, 1977.

[13] CEB-FIP: Model Code 1990, Final Draft, Committee Euro-International du Beton, Bulletin n. 213/214, Lausanne, Switzerland, 1990.

[14] L.A. Lutz and P. Gergely, "Mechanics of Bond and Slip of Deformed Bars in Concrete", ACI Journal, Volume 64, Issue 11, Pp. 711-721, 1967.

[15] K. Lundgren and K. Gylltoft, "A Model for Bond between Concrete and Reinforcement", Magazine of Concrete Research, Volume 52, Issue 1, Pp. 53-63, 2000.

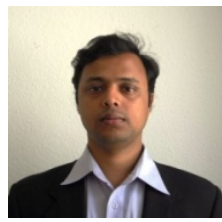

M.H. Mazumder, BSc \& MSc in Civil Engg. (BUET, Bangladesh), MSc in Civil Engg. (Bauhaus University Weimar, Germany). Maruful Hasan Mazumder was born in Bangladesh and graduated from Bangladesh University of Engineering and Technology (BUET) with a Bachelors and a Masters degree in Civil Engineering. He completed his second Masters degree in Structural Engineering, in Germany, where he was awarded the prestigious Deutsche Akademischer Austautch Dienst (DAAD) Scholarship. He is now undertaking a $\mathrm{PhD}$ at the University of New South Wales, where he holds an Australian Postgraduate Award. He is also working as a Research Assistant at the UNSW Centre for Infrastructure Engineering and Safety.

Maruful's research interests are in the area of structural engineering and computational mechanics. His $\mathrm{PhD}$ research is about the anchorage of reinforcement in concrete structures subjected to loadings and environmental extremes. Important findings of his $\mathrm{PhD}$ research have, so far, been published in 2 conference papers. The work of his Bachelor and Master theses has also been published in referred journals. (E-mail: z3319514@student.unsw.edu.au)

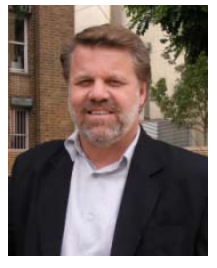

Professor R.I. Gilbert, BE, PhD (UNSW), FIEAust, MACI, CPEng Ian Gilbert is Emeritus Professor of Civil Engineering in the School of Civil and Environmental Engineering at the University of New South Wales. He is Deputy Director of the UNSW Centre for Infrastructure Engineering and Safety and has over 35 years experience working both in academia and as a consultant to the concrete industry. $\mathrm{He}$ is an elected member of the National Council of the Concrete Institute of Australia. His main research interests are in the area of serviceability of reinforced and prestressed concrete structures and he has published 5 books and over 300 papers in refereed journals and conferences. His books include "Time Effects in Concrete Structures" (Elsevier Science Publishers, Amsterdam, 1988), "Design of Prestressed Concrete" (E\&FN Spon, London, 1997), "Engineering 
Statics" (UNSW Press, Sydney, 1999) and "Time-Dependent Behaviour of Concrete Structures" (Spon Press, London, 2010). Professor Gilbert has been actively involved in the development of the Australian Standard AS3600 for over 30 years. (E-mail: i.gilbert@unsw.edu.au)

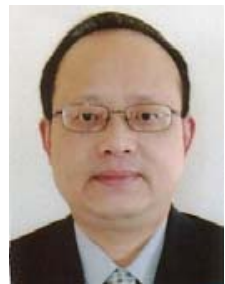

Dr. Z.T. Chang, PhD (UNSW), Zhen-Tian Chang is a senior research fellow in the Centre for Infrastructure Engineering and Safety (CIES), School of Civil and Environmental Engineering, the University of New South Wales, Australia. He has been associated with the UNSW since 1990. His main research interests are structural engineering, corrosion of steel reinforcement, durability of infrastructures in aggressive environments, and diagnosis and repair of RC structures. (E-mail: z.chang@unsw.edu.au) 